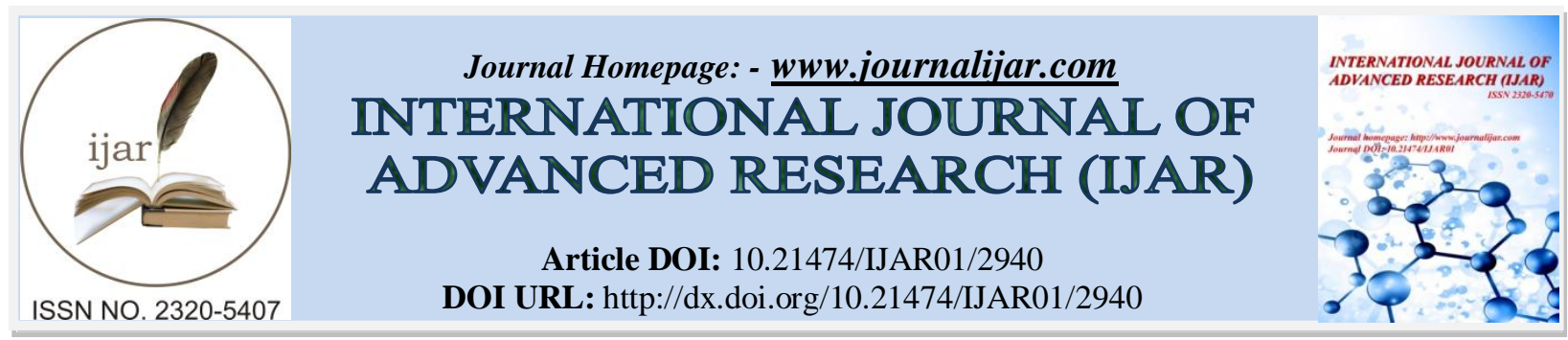

RESEARCH ARTICLE

\title{
PREVALENCE OF PARENTAL SELF MEDICATION AND ITS POSSIBLE EFFECT TO THEIR CHILDREN IN AL-MADINAH , KINGDOM OF SAUDI ARABIA.
}

Mahmoud Alkhayat, Nisreen Albouq*, Abdulaziz Osailan, Hatem Alharbi, Hind Alharbi and Rayan Alharbi. Faculty of Medicine, Taibah University, Al-Madinah Al-Munawwarah, Kingdom of Saudi Arabia.

\section{Manuscript Info}

Manuscript History

Received: 25 November 2016

Final Accepted: 27 December 2016

Published: January 2017

Key words:-

children, parents, self medication.

\section{Abstract}

Background : Self medication refers to the treatment of common health problems with medicines approved as safe and effective for use without consulting a physician and without any medical supervision.

Objective :The aim of the present study were to determine the prevalence of parental self-medication among children in Almadinah,Saudi Arabia, and parental knowledge and attitude about common medicine use practices in children ,in addition to the factors influencing self-medication.

Methods: A cross-sectional study was conducted. convenient random sampling method was used to select the participants. Data were collected using an online questionnaire tool.

Results : A total of 170 participants from Almadinah were involved in the study $50 \%$ of the them were fathers, and $50 \%$ were mothers .Most of them didn't have health insurance, while only $23 \%$ of them had. $63 \%$ of the sample use medicines without medical prescription for their children. We notice that $83 \%$ of the participants' children haven't been suffering any chronic disease. High temperature is the most popular case in which the parents use medicines without medical prescription for their children, then colds. The most used medication was Antipyretic. It can be noted that the majority of parents were giving their children drugs without a prescription, although they are convinced of the seriousness of the use of medications without a prescription. Parents depend on old medical prescription and pharmacist as major sources of information at self-medication.

Conclusion : The study revealed the fact that parental self-medication among public in Almadimah is a routine practice. we suggested that Parents' should be awareness about the riskiness of self-medication, especially in children to ensure that they will receive best medical Care. 


\section{Introduction:-}

Self medication refers to the treatment of common health problems with medicines approved as safe and effective for use without consulting a physician and without any medical supervision. This practice is widespread around the world ${ }^{(1)}$. The practice of self-medication among children consider really important since they constitute a large percentage of the population in developing countries and are prone to many illnesses (2). Unjustified and inappropriate self-medication results in wastage of healthcare resources and increases resistance of pathogens, drugdrug interactions, and adverse drug reactions leading to hospital admissions ${ }^{(3-6)}$.Younger children are often given medications by their parents because the first response by most families to many illnesses in their children has been found to be the use of non-prescribed drugs. Paediatric OTC drugs cover a wide range of medications including cough and cold medicines (CCMs), antipyretic analgesics (e.g. paracetamol and ibuprofen), vitamin supplements and dermatological products, antibiotics, antispasmodic agents etc. ${ }^{(7)}$ The conditions for which the drugs were used included fever, diarrhea, vomiting, cough and upper respiratory tract infections ${ }^{(8)}$.Most drugs in children are used to be administered outside hospitals, both as prescribed and non-prescribed ones ${ }^{(9)}$. Various studies have evaluated self-medication in children and reported higher rates of self-medication which was often inappropriate and parents were reported to have inadequate knowledge about self-medication ${ }^{(10,11)}$. To our knowledge, no information is available regarding the self-medication prevalence in the community in Saudi Arabia . Therefore, it is important to have data on self-medication in this area so that future interventions can be planned. Hence, the aim of the present survey carried out in the general population in Almadinah, were To determine the prevalence of parental selfmedication use among children in KSA, to investigate the effect of these medication to child's health and to know the factors influencing self-medication.

\section{Material and Methods:-}

A descriptive cross sectional study was undertaken among the population of Al- madinah, Kingdom of Saudi Arabia. A sample of (170) persons was selected randomly and answered the questionnaire randomly. The questionnaire was the study tool prepared by the research team with the help of experts and specialists in this field of study, the questionnaire contained four main sections; the first section represented the social and demographic data, which includes sex, age, job, living place, monthly income, health insurance availability, educational level, and the number of children, while the second section contained (5) questions to measure the spread of dispensing medicines without a medical prescription, the third section contained (7) questions in order to measure the awareness and behavior of the parents toward the dispensing without a prescription, and the fourth section aimed to know the factors affecting the dispensing without a prescription.

\section{Statistical Analysis:-}

The statistical analysis program (SPSS v.22) was been used in the study in data entry and analysis, with the use of necessary statistical methods to achieve the objectives of the study. The following statistical methods were used:

$>$ Frequencies.

$>$ Percentages.

$>$ Graphs.

$>$ Chi-square test.

\section{Results:-}

participants' distribution according to their personal and demographic data:

Table 1:- Personal data for the participants $(\mathrm{N}=170)$

\begin{tabular}{|l|l|l|l|}
\hline \multicolumn{2}{|l|}{ Variable } & $\#$ & $\%$ \\
\hline \multirow{2}{*}{ Gender } & Male (father) & 85 & $50 \%$ \\
\cline { 2 - 4 } & Female (Mather) & 85 & $50 \%$ \\
\hline \multirow{3}{*}{ Age (years) } & Less than 30 years & 65 & $38 \%$ \\
\cline { 2 - 4 } & More than 30 years & 105 & $62 \%$ \\
\hline \multirow{5}{*}{ Lccupation } & employee in the health field & 11 & $6 \%$ \\
\cline { 2 - 4 } & employee in unhealthy field & 99 & $58 \%$ \\
\cline { 2 - 4 } & unemployed & 60 & $35 \%$ \\
\hline \multirow{2}{*}{ Monthly income } & City & 164 & $96 \%$ \\
\cline { 2 - 4 } & Village & 6 & $4 \%$ \\
\hline
\end{tabular}




\begin{tabular}{|l|l|l|l|}
\hline & More than 10,000 r.s & 76 & $45 \%$ \\
\hline \multirow{2}{*}{ Do you have health insurance } & Yes & 39 & $23 \%$ \\
\cline { 2 - 4 } & No & 131 & $77 \%$ \\
\hline \multirow{2}{*}{ Education level } & Secondary or less & 29 & $17 \%$ \\
\cline { 2 - 4 } & Collectors or more & 141 & $83 \%$ \\
\hline \multirow{3}{*}{ Number of children } & $1-3$ & 106 & $62 \%$ \\
\cline { 2 - 4 } & $4-6$ & 44 & $26 \%$ \\
\cline { 2 - 4 } & More than 6 & 20 & $12 \%$ \\
\hline
\end{tabular}

It is clear from the previous table that $50 \%$ of the participants were fathers, and $50 \%$ were mothers, $62 \%$ of their ages were more than 30 years old, while $28 \%$ of them were less than 30 years old.

And their distribution according to their jobs; $58 \%$ of them were employee in the health field, only $6 \%$ were working in the health field, and the rest of them were unemployed. And the participants' distribution according to their living place, most of them were living in cities.

We found that $45 \%$ of the participants' monthly incomes were more than (10000) Riyal, $31 \%$ of their incomes were between (5000-10000) Riyal, and 24\% of their incomes were less than (5000) Riyal.

While their distribution in terms of having health insurance; most of them didn't have health insurance, while only $23 \%$ of them had.

$83 \%$ of the participants had university degrees, and the rest had secondary certificates or less.

Finally their distribution according to the number of their children; $62 \%$ of them had from (1- 3) children, $26 \%$ of them had (4- 6) children, and $12 \%$ of them had more than 6 children.

The next ( diagram 1) concludes the previous results.

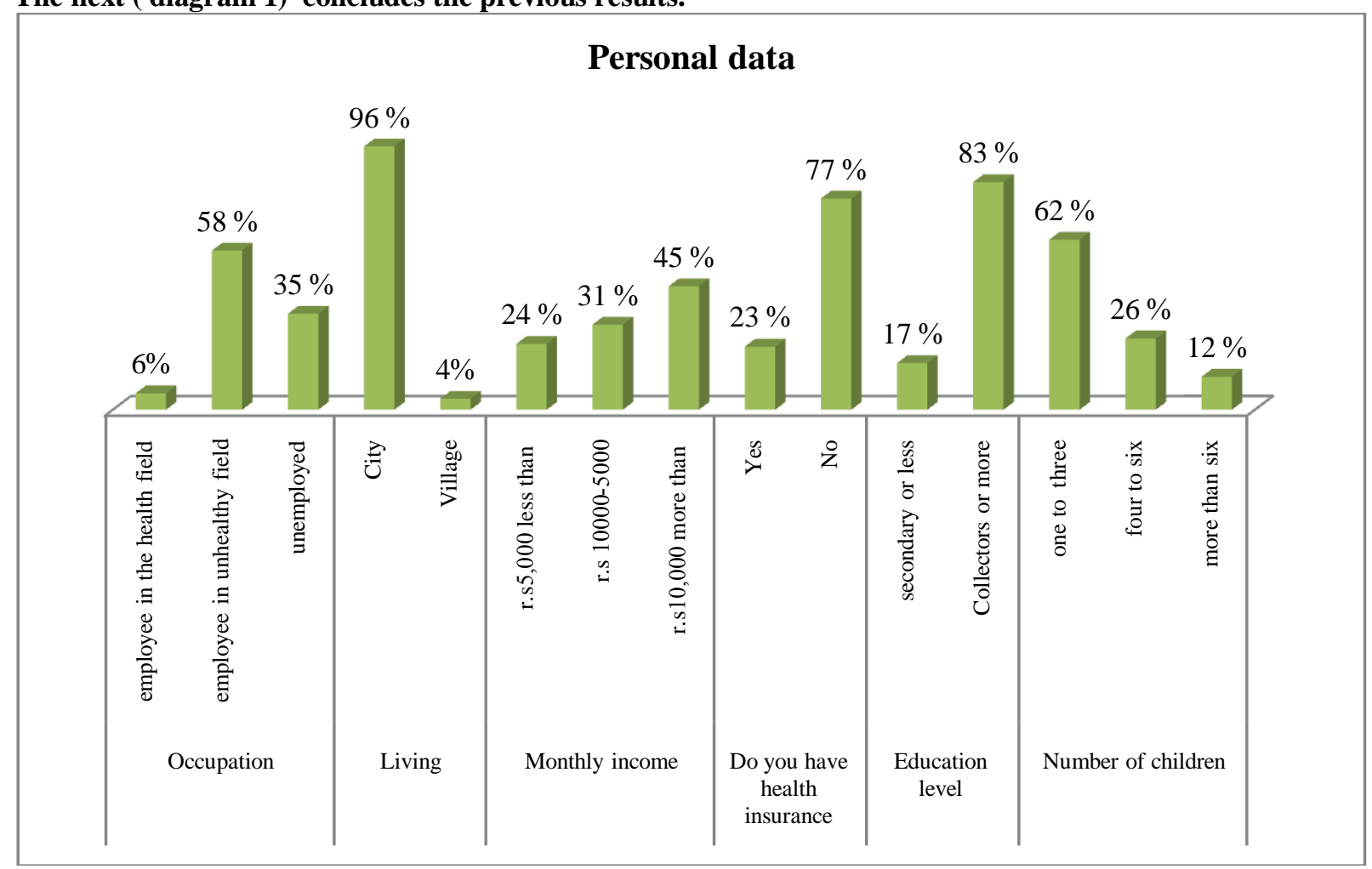




\section{Measuring of the spread of dispensing medicines without a medical prescription:}

The next( table 2) shows the participants' distribution according to using medicines for their children without edical prescription:

\begin{tabular}{|c|c|c|}
\hline Answer & $\#$ & $(\%)$ \\
\hline Yes & 107 & 62.9 \\
\hline No & 63 & 37.1 \\
\hline Total & 170 & 100.0 \\
\hline
\end{tabular}

We notice from the previous table that $63 \%$ of the sample members (mothers and fathers) use medicines without medical prescription for their children.

Then next (table 3) shows the participant's distribution whether their children have been suffering chronic diseases or not:

\begin{tabular}{|c|c|c|}
\hline Answer & $\#$ & $(\%)$ \\
\hline Yes & 29 & 17.1 \\
\hline No & 141 & 82.9 \\
\hline Total & 170 & 100.0 \\
\hline
\end{tabular}

We notice that $83 \%$ of the participants' children haven't been sufferring any chronic disease, while $17 \%$ of their children have been suffering chronic diseases; as diabetes and asthma.

The next ( diagram 2) shows the most popular cases in which the parents use medicines without medical prescription for their children:

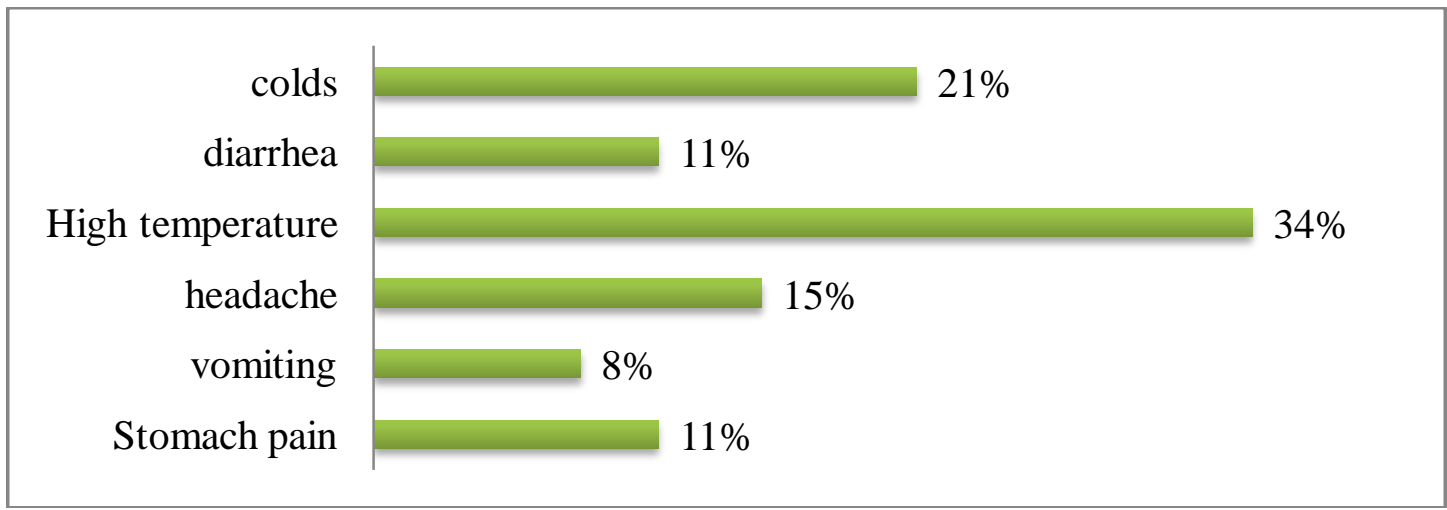

We notice from the table that (high temperature) is the most popular case in which the parents use medicines without medical prescription for their children, then colds, after that headache, diarrhea, stomach pain and vomiting ordered from the most to the least cases they may use medicines without medical prescription for their children.

The next ( diagram3) shows the most used medicines without medical prescription:

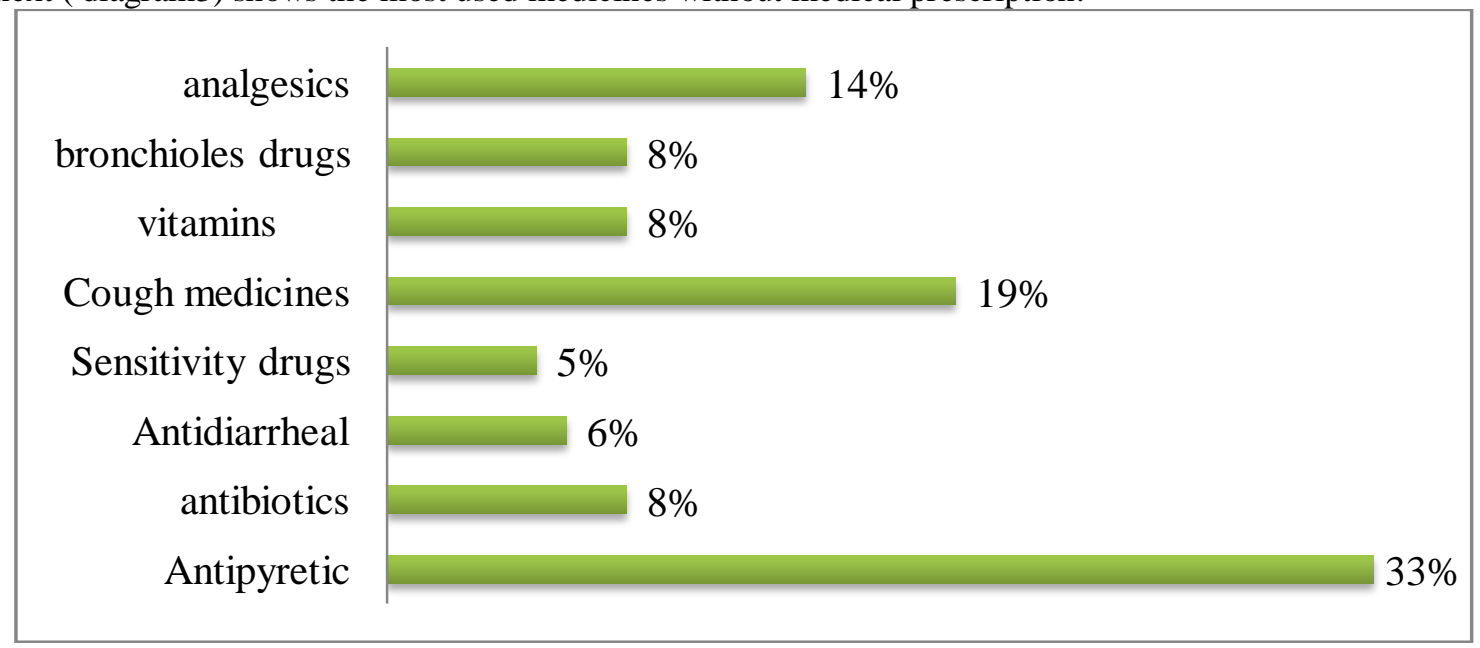


It is noticed that the most used ones was as the following order:

Antipyretic, Cough medicines, bronchioles drugs, analgesics, antibiotics, vitamins, Antidiarrheal and sensitivity drugs.

Measuring the awareness and behavior of the parents toward the dispensing without a prescription ( table 4 )

\begin{tabular}{|c|c|c|c|c|c|c|}
\hline & $\underset{\circlearrowright}{\mathscr{E}}$ & 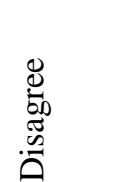 & 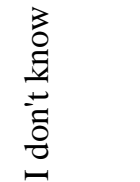 & & $\frac{\vec{E}}{.00}$ & \\
\hline & $\#(\%)$ & $\#(\%)$ & $\#(\%)$ & 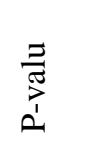 & 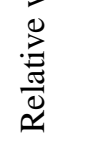 & $\frac{\stackrel{0}{\Xi}}{\stackrel{\Xi}{\Xi}}$ \\
\hline $\begin{array}{l}\text { when the child's temperature is high, he should be } \\
\text { given antipyretic }\end{array}$ & $\begin{array}{l}161 \\
(94.7)\end{array}$ & $6(3.5)$ & $3(1.8)$ & $0.00 * *$ & $97 \%$ & 1 \\
\hline $\begin{array}{l}\text { when the child's temperature is high, he should be } \\
\text { given antibiotic }\end{array}$ & $\begin{array}{l}17 \\
(10.0)\end{array}$ & $\begin{array}{l}135 \\
(79.4)\end{array}$ & $\begin{array}{l}18 \\
(10.6)\end{array}$ & $0.00 * *$ & $44 \%$ & 7 \\
\hline $\begin{array}{l}\text { No side effects will result cause of using medicines } \\
\text { without medical prescription }\end{array}$ & $\begin{array}{l}20 \\
(11.8)\end{array}$ & $\begin{array}{l}115 \\
(67.6)\end{array}$ & $\begin{array}{l}35 \\
(20.6)\end{array}$ & $0.00 * *$ & $48 \%$ & 6 \\
\hline $\begin{array}{l}\text { Use of medications without a good recipe leads to } \\
\text { hide the symptoms of the disease and the difficulty } \\
\text { of diagnosis }\end{array}$ & $\begin{array}{l}78 \\
(45.9)\end{array}$ & $\begin{array}{l}25 \\
(14.7)\end{array}$ & $\begin{array}{l}67 \\
(39.4)\end{array}$ & $0.00 * *$ & $77 \%$ & 5 \\
\hline $\begin{array}{l}\text { I think many parents are using drugs without a } \\
\text { prescription }\end{array}$ & $\begin{array}{l}117 \\
(68.8)\end{array}$ & $\begin{array}{l}20 \\
(11.8)\end{array}$ & $\begin{array}{l}33 \\
(19.4)\end{array}$ & $0.00 * *$ & $86 \%$ & 4 \\
\hline $\begin{array}{l}\text { parents should be told about the danger of using } \\
\text { drugs without a prescription }\end{array}$ & $\begin{array}{l}148 \\
(87.1)\end{array}$ & $12(7.1)$ & $10(5.9)$ & $0.00 * *$ & $93 \%$ & 3 \\
\hline $\begin{array}{l}\text { The physician should diagnose the disease and make } \\
\text { the necessary tests before treatment description }\end{array}$ & $\begin{array}{l}156 \\
(91.8)\end{array}$ & $10(5.9)$ & $4(2.4)$ & $0.00 * *$ & $95 \%$ & 2 \\
\hline
\end{tabular}

**Chi Square test - Significant at the 0.01 level.

It is noted from the (table 4) that most paragraphs won the highest approval rate by the participants: the paragraph which states that "when the high temperature of the child should be given antipyretic," came the first order of relative weight of $97 \%$, followed by a paragraph which states "must The doctor diagnosed the disease and the work of the necessary tests before treatment Exchange, "a relative weight of 95\%.

It can be noted that the majority of parents were giving their children drugs without a prescription, although they are convinced of the seriousness of the use of medications without a prescription.

The factors affecting the dispensing without a prescription:-

The next (diagram 4) shows the most important reasons lead the parents to use medicines without a prescription for their children. 


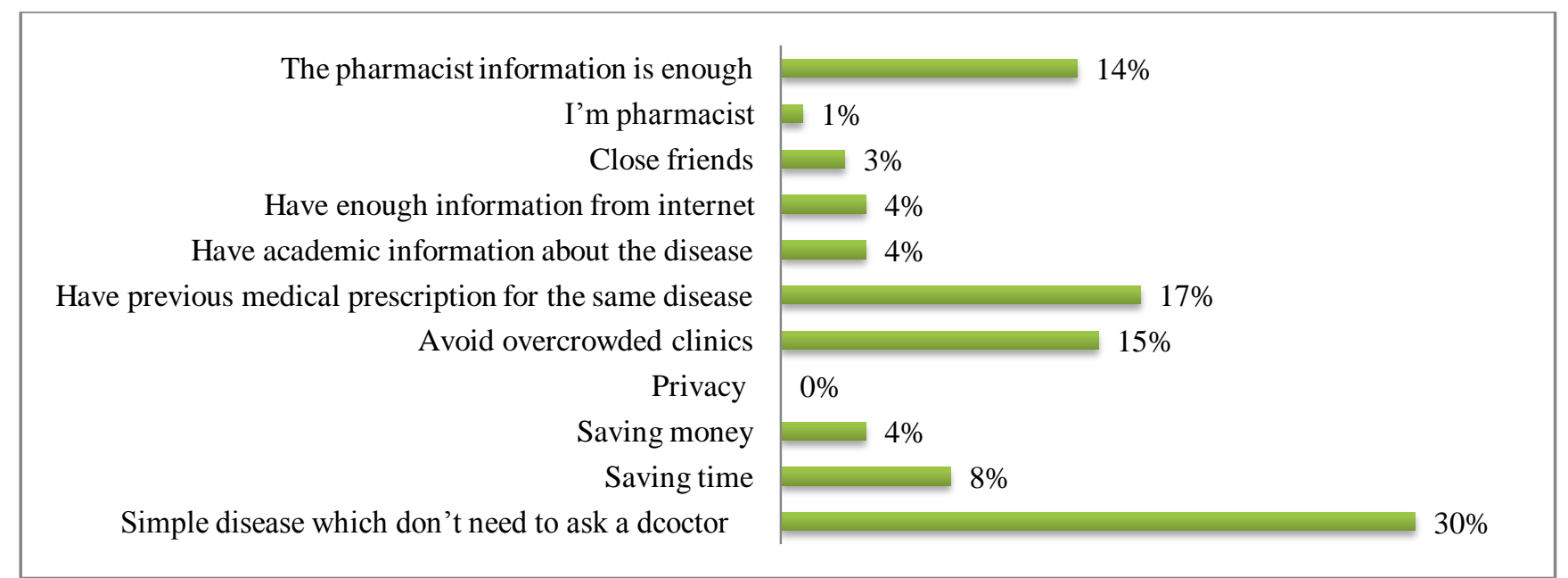

It is clear from the previous diagram that the most important reasons made the parents use medicines without a prescription for their children, were ordered as follows (Simple disease which don't need to ask a doctor, have previous medical prescription for the same disease, avoid overcrowded clinics, the pharmacist information is enough and saving time).

\section{Discussion:-}

Self-medication is still an important public health problem throughout the world, since it is a fairly common practice. Unjustified and inappropriate self-medication results in wastage of healthcare resources and increases resistance of pathogens, drug-drug interactions, and adverse drug reactions leading to hospital admissions $[12,13,14,15]$. Most of the studies on self-medication in children have investigated the use of medicines by children themselves [16,17]. Few studies have evaluated parental attitude and practice towards self-medicating their children[18,19,20]. Therefore this study has highlighted the prevalence of parental self-medication use among children , and parental knowledge and attitude about common medicine use practices in children in KSA, in addition to the factors influencing self-medication.

At the current study participants were divided into males and females equally, this showed that both parentsinvolved in dealing with health problems of their children. However study in India showed that most of respondents were female [21] which indicates that mothers are more involved in dealing with health problems of their children. While in Baghdad city fathers purchasing self- medicated were relatively more than mothers [22], the possible explanation of this slight difference is that some women considered that the father is more appropriate for this mission or they could not leave their homes without companionship of a male relative from the first degree [23].

Despite the lack of evidence for the effectiveness of many over-the-counter (OTC) medications [24,25], and the possible risks associated with their improper use among young children, [26,27], they remain widely used [28].The results of our study showed high prevalence of parental self-medication use among children $62.9 \%$. These results are consistent with another study in Saudi Arabia reported that $53.8 \%$ of the parents practiced self-medication in their children [29]. This proportions consistent with the global variation of prevalence of self-medication which has been reported by various studies to range between 30-70\% [30]. The reasons for such huge global variation many be numerous including different methods used for collecting information, availability of free medical care for children in the public sector hospitals in some countries[31]. Also cultural, social and educational factors have been shown to affect self-medication [29].

The common ailments of children including headache, fever, flu, diarrhoea and sore throat can be treated at home [32]. This study revealed that the most frequent symptoms which motivated the parents to practice self-medication for their children werefever followed by colds, headache, diarrhea, stomach pain and vomiting respectively. This is consistent with most of the other studies on parental self-medication in children which reported that fever, cough and cold as the common symptoms for using medicines without consulting a doctor [19,20,21,29]. Also our study revealed that the most common used drug were Antipyretic, Cough medicines, and bronchioles drugsrespectively. 
According to our results parents showed good awareness and behavior toward the dispensing without a prescription, there is contradict between this results and previous study in KSA which reported that most participants had poor knowledge positive attitude toward self-medications[33].The reason for the different in results, the is time difference between the two studies, and the difference in regions that were targeted by these two studies in the KSA.

In the present study $11.8 \%$ of parents believed that no side effects will result cause of using medicines without medical prescription. While most of parents believed that side effects will result cause of using medicines without medical prescription. These results differed with study from UK found that parents were generally unaware of potential side effects of OTC medicines because they believed that "over-the-counter medicines are not strong and were unlikely to harm their child," [34]. And study from Japan reported little awareness about adverse effects of non-prescription medicines among participants[35].This difference is due to different at sociodemographic indicators in different countries.

At this study the reasons of Self-medication are Varied, the most common reason was that the disease is simple which don't need to ask a doctor. Actually some minor ailments can be relieved with SM medications such as Paracetamol or other traditional remedies, without seeking for consultation from general practitioners or pediatricians [32].

Parents knowledge and information of the children's ailments may be obtained from doctors, pediatrics, pharmacists, friends, books, magazines, newspaper or the internet [36]. The commonest source of information about self-medicated drugs at our study, and at many other studies was old medical prescription [22,37]. Because parents considered that the prescription will be the same if they visited the physician and also considered that they had good experience and became familiar with the appropriate medication for managing this current condition [38].

Also pharmacist information represent another other important source of information for parents at children's ailments and it the reason for $14 \%$ for self-medication. this is consistent with the results of other studies Saudi Arabia [23], in Iraq [22], and Indonesia [39], that's considered pharmacist information as one of the major sources of information for parents at children's ailments. Which highlight the important roles of community pharmacies in wide pervasion of SM in the community[40].

Although regulations do not allow pharmacists to prescribe drugs, this may be explained by the fact they are more easily accessible and the service is faster.

\section{Conclusion:-}

There is high prevalence of parental self-medication use among children in KSA. However parents showed good awareness and behavior toward the dispensing without a prescription. The major reason for self-medication the simplicity of disease or symptoms so it don't need a doctor. The most frequent symptoms which motivated the parents to practice self-medication for their children are fever followed by colds, headache, diarrhea, stomach pain and vomiting respectively. And the most common used drug are Antipyretic, Cough medicines, and bronchioles drugs respectively. Parents depend on old medical prescription and pharmacist as major sources of information at self-medication.

\section{Recommendation:-}

- Parents' should be awareness about the riskiness of self-medication, especially in children.

- Distributing brochures to parents about the riskiness of self-medication in centers of vaccinate children to ensure they arrive for most parents.

- Exploit the various media effectively to raise awareness among parents about the riskiness of self-medication.

- Pharmacists should committed to regulations which do not allow pharmacists to prescribe drugs.

- Pharmacists can play crucial roles in enhancing the proper practicing of self-medication because they are reliable sources of information for many parents.

\section{Acknowledgment:-}

The authors would like to thank Dr. Hany Mahmoud Abo-Haded, Assistant Professor of Pediatrics \&Pediatric Cardiology, TaibaUniversity, Medina, KSA, for his valuable input though revising the tools and the manuscript of this study. 


\section{References:-}

1. Chewning B, Sleath B. Medication decision-making and management: A client-centered model. SocSci Med., 1996; 42: 389-98.

2. Lee D, Balasubramaniam K, Ali H. Drug utilization studies: Their transferability between industrialized and developing countries. In: Dukes MNG, editor. Drug Utilization Studies. Methods and uses. Copenhagen, World Health Organization Regional office Europe, 1993 (WHO Regional Publications, European Series, No. 45).

3. P. Olivier, L. Bertrand, M. Tubery, D. Lauque, J.-L. Montastruc, and M. Lapeyre-Mestre, "Hospitalizations because of adverse drug reactions in elderly patients admitted through the emergency department: a prospective survey," Drugs \& Aging, vol. 26, no. 6, pp. 475-482, 2009. View at Publisher •

4. D. Lewinski, S. Wind, C. Belgardt, V. Plate, C. Behles, and H. G. Schweim, "Prevalence and safety-relevance of drug-related problems in German community pharmacies," Pharmacoepidemiology and Drug Safety, vol. 19, no. 2, pp. 141-149, 2010. View at Publisher .

5. C. Eickhoff, A. Hämmerlein, N. Griese, and M. Schulz, "Nature and frequency of drug-related problems in selfmedication (over-the-counter drugs) in daily community pharmacy practice in Germany," Pharmacoepidemiology and Drug Safety, vol. 21, no. 3, pp. 254-260, 2012.

6. N. Asseray, F. Ballereau, B. Trombert-Paviot et al., "Frequency and severity of adverse drug reactions due to self-medication: a cross-sectional multicentre survey in emergency departments," Drug Safety, vol. 36, no. 12, pp. 1159-1168, 2013.

7. Zaki A, Abdel-Fattah M, Bassili A, Arafa M, Bedwani R. The use of medication in infants in Alexandria, Egypt. Eastern Mediter Health J 1999;5:320-7.

8. Sharma R, Verma U, Sharma CL, Kapoor B. Selfmedication among urban population of Jammu city. Indian J Pharmacol 2005;37:37-45.

9. Fosarelli P, Wilson M, De Angelis C. Prescription medications in infancy and early childhood. Am J Dis Child 1987;141:772-5.

10. Eldalo AS. Saudi parent's attitude and practice about self-medicating their children. Arch PharmaPract, 2013; 4: 57-62.

11. Eldalo AS, El-Hadiyah TM, Yousif M A. Sudanese parents' knowledge, attitudes and practice about selfmedication to their children: Qualitative study. Saudi J Health Sci., 2013; 2: 103-7.

12. Olivier, Pascale, et al. "Hospitalizations because of adverse drug reactions in elderly patients admitted through the emergency department." Drugs \& aging26.6 (2009): 475-482.

13. Lewinski, Daniel, et al. "Prevalence and safety-relevance of drug-related problems in German community pharmacies." Pharmacoepidemiology and drug safety 19.2 (2010): 141-149.

14. Eickhoff, Christiane, et al. "Nature and frequency of drug-related problems in self-medication (over-the-counter drugs) in daily community pharmacy practice in Germany." Pharmacoepidemiology and drug safety 21.3 (2012): 254-260.

15. Asseray, Nathalie, et al. "Frequency and severity of adverse drug reactions due to self-medication: a crosssectional multicentre survey in emergency departments." Drug safety 36.12 (2013): 1159-1168.

16. Du, Yong, and Hildtraud Knopf. "Self-medication among children and adolescents in Germany: results of the National Health Survey for Children and Adolescents (KiGGS)." British journal of clinical pharmacology 68.4 (2009): 599-608.

17. Buck, Marcia L. "Self-medication by adolescents." Pediatr Pharm 13.5 (2007): 1-4.

18. Eldalo, Ahmed S. "Saudi parent's attitude and practice about self-medicating their children." Archives of Pharmacy Practice 4.2 (2013): 57.

19. Eldalo, Ahmed S., Tarig MH El-Hadiyah, and M. A. Yousif. "Sudanese parents' knowledge, attitudes and practice about self-medication to their children: Qualitative study." Saudi Journal for Health Sciences 2.2 (2013): 103 .

20. Tibdewal, Sunita, and Madhur Gupta. "Mother's use of medication in their children of preschool age." Indian journal of public health 49.1 (2005): 27.

21. Sontakke, Smita, et al. "EVALUATION OF PARENTAL PERCEPTION ABOUT SELF-MEDICATION AND OTHER MEDICINE USE PRACTICES IN CHILDREN."

22. Jasim, Ali Lateef. "PARENTAL SELF MEDICATION OF ANTIBIOTICS FOR CHILDREN IN BAGHDAD CITY." International Journal of Pharmacy and Pharmaceutical Sciences 6.10 (2014): 485-489.

23. Alghanim, S. A. "Self-medication practice among patients in a public health care system/Pratique de l'automédication chez les patients bénéficiant d'un système de soins de santé public." Eastern Mediterranean health journal 17.5 (2011): 409. 
24. Schroeder, Knut, and Tom Fahey. "Systematic review of randomised controlled trials of over the counter cough medicines for acute cough in adults." Bmj324.7333 (2002): 329.

25. Smith, Michael BH, and William Feldman. "Over-the-counter cold medications: a critical review of clinical trials between 1950 and 1991." Jama 269.17 (1993): 2258-2263.

26. Gadomski, Anne. "Rational use of over-the-counter medications in young children." JAMA 272.13 (1994): 1063-1064.

27. Gunn, Veronica L., et al. "Toxicity of over-the-counter cough and cold medications." Pediatrics 108.3 (2001): e52-e52.

28. Allotey, Pascale, Daniel Diamond Reidpath, and Danielle Elisha. "'Social medication" and the control of children: a qualitative study of over-the-counter medication among Australian children." Pediatrics 114.3 (2004): e378-e383.

29. Eldalo, Ahmed S. "Saudi parent's attitude and practice about self-medicating their children." Archives of Pharmacy Practice 4.2 (2013): 57.

30. Alele, Peter Micheal. Self-medication practices by caretakers for children under five years in Tororo District. Diss. Makerere University, 2013.

31. Aoyama, Ikuko, Shinichi Koyama, and Haruo Hibino. "Self-medication behaviors among Japanese consumers: sex, age, and SES differences and caregivers' attitudes toward their children's health management." Asia Pacific family medicine 11.1 (2012): 1.

32. Dawood, Omar T., Mohamed IM Ibrahim, and SubishPalaian. "Parent's knowledge and management of their children's ailments in Malaysia." Pharm Pract (Internet) 8.2 (2010): 96-102.

33. Aljadhey, Hisham, et al. "Self-medication in Central Saudi Arabia: Community pharmacy consumers' perspectives." Saudi medical journal 36.3 (2015): 328.

34. Birchley, Nicola. "Parental management of over-the-counter medicines." Nursing Children and Young People 14.9 (2002): 24.

35. Aoyama, Ikuko, Shinichi Koyama, and Haruo Hibino. "Self-medication behaviors among Japanese consumers: sex, age, and SES differences and caregivers' attitudes toward their children's health management." Asia Pacific family medicine 11.1 (2012): 1.

36. Pandolfini, Chiara, PieroImpicciatore, and Maurizio Bonati. "Parents on the web: risks for quality management of cough in children." Pediatrics 105.1 (2000): e1-e1.

37. Kariyawasam, S. H., et al. "A descriptive cross sectional study on mothers self-medicating children." (2005).

38. Awad, Abdelmoneim, et al. "Self-medication with antibiotics and antimalarials in the community of Khartoum State, Sudan." J Pharm PharmSci 8.2 (2005): 326-331.

39. Widayati, Aris, et al. "Self medication with antibiotics in Yogyakarta City Indonesia: a cross sectional population-based survey." BMC research notes 4.1 (2011): 1.

40. James, H., et al. "Influence of medical training on self-medication by students." International journal of clinical pharmacology and therapeutics 46.1(2008):23-29 